\title{
Prostate Cancer Screening by General Practitioners in Lomé, Togo
}

\author{
Tchilabalo Matchonna Kpatcha ${ }^{*}$, Tchin Darré2, Edoe Viyome Sewa ${ }^{3}$, Komi Hola Sikpa1, \\ Gnimdou Botcho', Essodina Padja ${ }^{3}$, Essomendedou Adolphe Leloua ${ }^{3}$, Kodjo Tengue ${ }^{3}$ \\ ${ }^{1}$ Department of Urology, University Teaching Hospital of Kara, Kara, Togo \\ ${ }^{2}$ Department of Pathology, University Teaching Hospital of Lomé, Lomé, Togo \\ ${ }^{3}$ Department of Urology, University Teaching Hospital of Lomé, Lomé, Togo \\ Email: ‘fakpatcha@yahoo.fr, paolodarre@yahoo.fr, viyomedoe35@yahoo.fr, docjno@yahoo.fr, aristbo@yahoo.fr, \\ padjarodrigue@yahoo.fr, lladoles@yahoo.fr, drtenguekodjo@yahoo.fr
}

How to cite this paper: Kpatcha, T.M., Darré, T., Sewa, E.V., Sikpa, K.H., Botcho, G., Padja, E., Leloua, E.A. and Tengue, K. (2022) Prostate Cancer Screening by General Practitioners in Lomé, Togo. Open Journal of Urology, 12, 27-36.

https://doi.org/10.4236/oju.2022.121003

Received: October 7, 2021

Accepted: January 11, 2022

Published: January 14, 2022

Copyright $\odot 2022$ by author(s) and Scientific Research Publishing Inc. This work is licensed under the Creative Commons Attribution International License (CC BY 4.0).

http://creativecommons.org/licenses/by/4.0/

\begin{abstract}
Background: Prostate cancer is a common disease in men over 50 years. Only early detection by screening can guarantee a favourable outcome. Objective: The objective of the study is to report on the practice of prostate cancer screening by general practitioners in Lomé. Material and Method: This was a practice survey. A questionnaire administered to general practitioners allowed to examine the following parameters: the practitioner's years of practice, the screening criteria, the screening tools and the factors motivating the request for urological advice. The data were analysed using the software Epi info 7.1.5. The $\mathrm{P}$ value was considered significant below 0.05. Results: One hundred and eighty (180) physicians average-aged 29 were administered among whom one hundred and fifty-seven (157) males and twenty-three (23) females. The average duration of the medical practice was 35.2 months (6 months - 204 months). The screening criteria were age (47.2\%), family history of cancer (17.8\%), and age over 50 years associated with symptoms of the low urinary tract $(35 \%)$. The practitioner's experience did not affect these criteria $(\mathrm{p}=0.12)$. The screening tools were the digital rectal examination (DRE) associated with prostate specific antigen (PSA) assay (20.5\%), PSA alone (29.5\%), DRE alone (6.6\%), suprapubic ultrasound (32.3\%) and endorectal ultrasound (11.1\%). The choice of the screening tool was related to the practitioner's experience $(\mathrm{p}=0.03)$. The determining factor for a urological consultation was a high PSA ( $>4 \mathrm{ng} / \mathrm{ml})$ independent of the DRE. Conclusion: Prostate cancer screening is largely done by general practitioners in Lomé. However, the use of some criteria and tools for the screening is not optimal.
\end{abstract}

\section{Keywords}

Prostate Cancer, Screening, Survey, Lomé, Togo 


\section{Introduction}

Prostate cancer is a major concern due to its frequency (most common urological cancer, second most common cancer in men) and mortality (sixth cause of cancer death in men) [1] [2]. Although prostate cancer is a global public health issue, its mass screening is controversial. This is still so despite the fact that studies have reported a gain in overall survival (European Randomized Study of Screening for Prostate Cancer (ERSPC)) [3]. The risk of overdiagnosis and overtreatment has been a reality since the advent of PSA and its wide use [4] [5]. In Africa, the diagnosis is often done with a predominance of metastatic forms at diagnosis (from the outset metastatic) and very high mortality [6]. According to GLOBOCAN, the incidence of prostate cancer will increase significantly in Africa in the coming decades; the greatest impact will be recorded by 2040 in Africa, followed by Latin America and the Caribbean and Asia [7]. Unlike developed countries where the problem of overdiagnosis and overtreatment arises, prostate cancer is characterized in Africa by a delay in diagnosis. In Togo, 85\% of patients with prostate cancer are diagnosed at the metastasis stage where therapeutic options are limited with high mortality [8]. Therefore, early detection represents a solution in the fight against prostate cancer mortality by allowing diagnosis at a stage accessible to curative treatment. Prostate cancer screening by general practitioners is an essential element in the screening activity because they are the ones who see the most patients often in the asymptomatic stage. This study was carried out to report on the practice of prostate cancer screening by general practitioners in Lomé in order to assess the screening activity of these practitioners.

\section{Materials and Methods}

\subsection{Type of Study}

This is a cross-sectional descriptive study based on a practice survey carried out in Lomé. The study length was three months (from April to June 2020), and the site was health centers of Lomé. We administered anonymous questionnaire to general practitioners.

\subsection{Sampling}

General practitioners who gave their consent and where regularly registered with the national order of doctors of Togo were enrolled. The minimum representative sample size $(n)$ was calculated on the basis of the following formula

$$
n=z^{2} \times p(1-p) / m^{2} .
$$

$z=1.65$ : value corresponding to $90 \%$ confidence level;

$p$ : Estimated proportion of study population who screen for prostate cancer $=$ 0.5 ;

$m$ : desired degree of accuracy $=0.07$;

$n=(1.65)^{2} \times 0.5(1-0.5) /(0.07)^{2}=138.9$. 
The minimum representative sample size $n=139$ practitioners.

All the physicians who filled the questionnaire were taken into consideration for the study. The questionnaire consisted of three main parts. The first part elicited the socio-demographic data and the number of years of medical practice. The second part was devoted to screening criteria and the tools used. The third part focused on the risk of cancer interpretation and the request or not for a urological consultation.

To check the reliability of the questionnaire, it has been tested on a small sample of ten practitioners. Following this test, improvements were made making it possible to develop the final questionnaire.

\subsection{Statistical Analysis}

The data analysis was carried out by the software Epi info 7.1.5. We used percentages for qualitative and median variables with their standard deviations for quantitative variables. The statistical tests used were Pearson Chi-square test for qualitative variables and Student test for quantitative variables. The significance threshold was 0.05 .

\section{Results}

One hundred and eighty (180) physicians took part in the study (the total number of physicians is 215) for a participation rate of $83.7 \%$. 157 representing $87.2 \%$ were male and the average age of all respondents was 29 . The medical practice average length was 35.2 months with extremes of 6 months and 204 months. The characteristics of the respondents are summarized in Table 1.

Table 1. Sociodemographic characteristics of practitioners.

\begin{tabular}{lc}
\hline & Value \\
\hline Age (Years) & 29 \\
1) Average & $27-52$ \\
2) Extremes & \\
Sex & $157 / 180$ \\
1) Male & $23 / 180$ \\
2) Female & \\
Medical practice length (months) & 35.2 \\
$1)$ Average & $6-204$ \\
2) Extremes & $58 / 180$ \\
$3) \leq 60$ months & $32 / 180$ \\
$4)>60 \leq 120$ months & $49 / 180$ \\
$5)>120$ months $\leq 180$ months & $41 / 180$ \\
$6)>180$ months & \\
Lesson on prostate cancer over last 60 months & \\
Yes & $45 / 180$ \\
No & $135 / 180$ \\
Total & 180 \\
\hline
\end{tabular}


The screening criteria for prostate cancer used were age only (age over 50 years) by $47.2 \%$ of physicians, family history of cancer by $17.8 \%$ and urinary symptomatology (symptoms of the lower urinary tract) associated with age (age over 50 years) by $35 \%$. The respondents unanimously considered an age of less than 50 as a criterion for exclusion from prostate cancer screening. The practitioner's experience did not influence the screening criteria $(\mathrm{p}=0.12)$, as well as the sex $(\mathrm{p}=0.35)$. The screening tools were digital rectal examination (DRE), prostate specific antigen (PSA) assay, suprapubic ultrasound and endorectal ultrasound as shown in Figure 1.

The choice of the screening tool was significantly related to the practitioner's experience $(\mathrm{p}=0.03$ ), with DRE-PSA being more used by practitioners over 10 years of experience in the profession, while the pubic ultrasound was the preferred exam by practitioners under 10 years of practice. The majority of participants $(83.8 \%)$ considered abnormal PSA and ultrasound abnormalities of the prostate to be the main findings for suspecting cancer. But the main criterion (76.6\%) that motivated the referral of the patient to the urologist was a PSA rate of at least $4 \mathrm{ng} / \mathrm{ml}$ regardless of the result of DRE and prostatic ultrasound.

\section{Discussion}

According to the study, prostate cancer screening is a major concern of general practitioners in Lomé although there is a large disparity in the choice of criteria and modalities for screening. The criteria for the screening are well identified. These include risk factors; the most important of which are age, family history of prostate cancer, genetic susceptibilities and environmental factors such as diet [9]. Age and genitourinary disorders have been identified as the primary

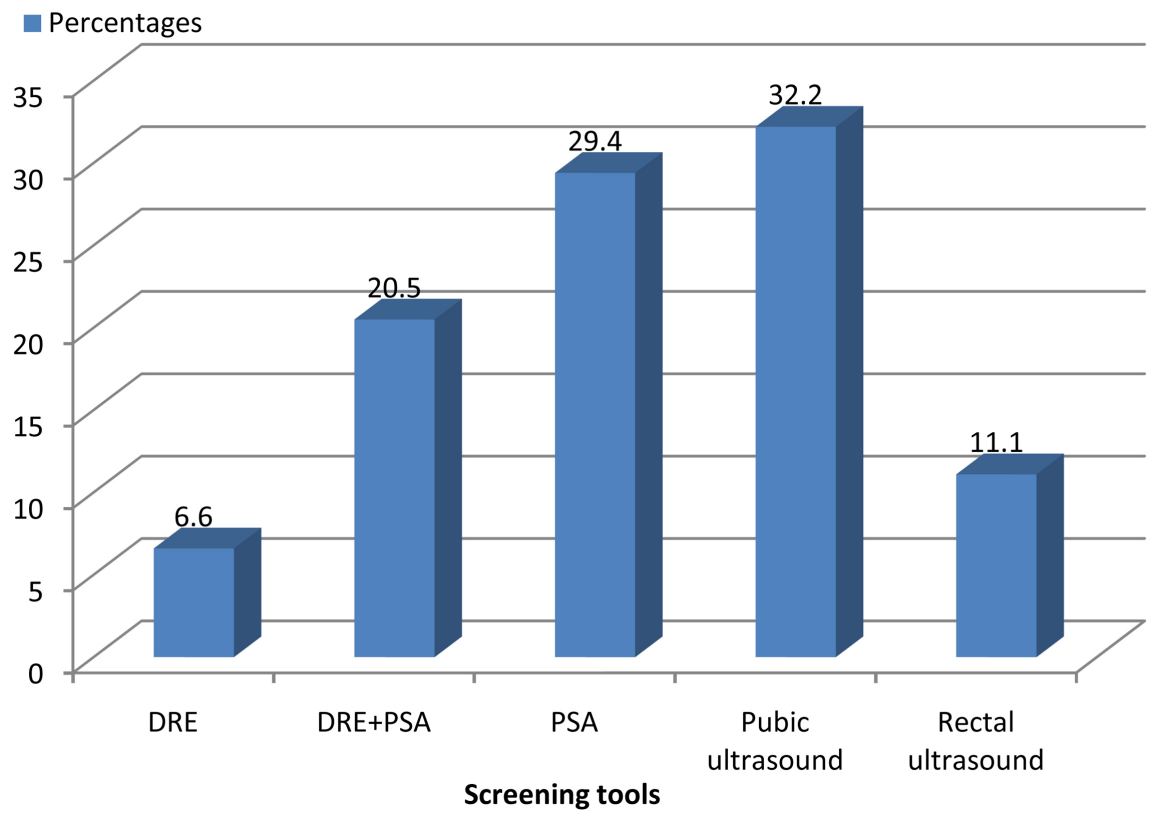

Figure 1. Distribution of prostate cancer screening tools used by practitioners. DRE = digital rectal examination; PSA = prostate specific antigen. 
screening criteria by practitioners and this is not consistent with current recommendations [10]. Systematic research on patients aged 50 or more needs to be considered and addressed in our region characterized by a high rate of delay in diagnosis and a weak screening policy. Family history of prostate cancer was only considered a risk factor by 48 physicians ( $26.6 \%$ of the respondents). This constitutes a major concern given the important role played by this factor in the early onset of prostate cancer. In addition to their early onset, family cancer appears to be more aggressive compared to sporadic forms [11] and thus reinforcing the beneficial role that systematic early cancer screening could play in Africa. However, recent studies on large series have questioned these conclusions [12].

Individual screening based on risk assessment for each patient reduces the risk of overdiagnosis without negating it, but active treatment is reserved only for patients in whom cancer is considered significant and the treatment is beneficial [13] [14]. Among the risk factors for prostate cancer, patients older than 45 years with a family history of prostate cancer and African descent are important factors supporting a massive prostate cancer screening in Africa since the risk of diagnosis at an advanced stage is more important in Africa [15] [16] [17]. The practice of prostate cancer screening is not yet up to date in general practitioner medicine. This practice, even though improves with professional experience, does not meet the recommendations of urologists.

The DRE used alone as a screening tool has low sensitivity and specificity and is therefore not recommended for the elimination of prostate cancer [18]. Although most cancers are located at the peripheral prostate, making it possible to detect a nodule from $0.2 \mathrm{ml}$ in volume, only $18 \%$ of cancers are detected by DRE alone, regardless of the PSA value [19]. Since the advent of PSA and its use as a front-line screening tool following Catalona's work in 1991 [1], the incidence of prostate cancer has exploded worldwide and the T1c clinical stage is widely diagnosed in Europe [20]. However, this stage is rare in Africa. The effect of PSA screening has been evaluated by many studies and the most important of which was the randomized Swedish Goetborg study. This study reported lower rates of advanced stage ( $41 \%$ less in the arm tested) and lower mortality (44\% less in the detected arm) in the screened arm compared to the non-screened arm [21] [22].

DRE and PSA represent the two screening tests. Although their interpretation is related, the normality of the two or one does not eliminate cancer. Thus, for a normal DRE with a PSA level less than or equal to $2 \mathrm{ng} / \mathrm{ml}$, the positive predictive value of prostate cancer varies between $5 \%$ and 30\% [23] while an abnormal DRE is associated with an increased risk of high ISUP grade prostate cancer [24] [25].

The PSA is a dynamic data whose value commonly defined as normal (4 ng/ $\mathrm{ml}$ ) is relative. Although high values increase the risk of prostate cancer, values below $4 \mathrm{ng} / \mathrm{ml}$ do not formally eliminate it and may even be related to cancers classified as ISUP 2 or higher as shown by Thomson et al. [26] (Table 2). 
Table 2. Risk of prostate cancer and ISUP grade $\geq 2$ for PSA values less than or equal to 4 $\mathrm{ng} / \mathrm{ml}[26]$.

\begin{tabular}{ccc}
\hline PSA level $(\mathrm{ng} / \mathrm{mL})$ & Risk of PCa (\%) & Risk of ISUP grade $\geq 2$ PCa $(\%)$ \\
\hline $0.0-0.5$ & 6.6 & 0.8 \\
$0.6-1.0$ & 10.1 & 1.0 \\
$1.1-2.0$ & 17.0 & 2.0 \\
$2.1-3.0$ & 23.9 & 4.6 \\
$3.1-4.0$ & 26.9 & 6.7 \\
\hline
\end{tabular}

This makes the logarithm decision for prostate cancer screening complex for the general practitioner since many cases could escape diagnosis and therefore increase the risk of late diagnosis for aggressive cancers. The best approach would be to refer all patients at risk (family history) to the urologist who will be able to weigh the benefits and risks of further exploration that can allow more efficient recruitment of patients to be treated.

Our study has some limitations common to all surveys, especially the low value of answers and their objectivity. However, the data collected allow an analysis of the reality of the practice of screening for prostate cancer in our conditions.

\section{Conclusion}

Prostate cancer screening by general practitioners of Loméis inefficient. The dosage of PSA is widely used but its interpretation is not optimal. Also, the results of the digital rectal examination are trifling in the suspicion of prostate cancer. On-going training of practitioners is needed to popularize the good practice of prostate cancer screening.

\section{Acknowledgements}

We Thank Professor ESSIZEWA Komlan for His Valuable Contribution.

\section{Conflicts of Interest}

The authors declare no conflicts of interest regarding the publication of this paper.

\section{References}

[1] Siegel, R.L., Miller, K.D. and Jemal, A. (2017) Cancer Statistics, 2017. CA: A Cancer Journal for Clinicians, 67, 7-30. https://doi.org/10.3322/caac.21387

[2] Ferlay, J., Soerjomataram, I., Dikshit, R., Eser, S., Mathers, C., Rebelo, M., et al. (2015) Cancer Incidence and Mortality Worldwide: Sources, Methods and Major Patterns in GLOBOCAN 2012. International Journal of Cancer, 136, E359-E38. https://doi.org/10.1002/ijc.29210 6.

[3] Schroder, F.H., Hugosson, J., Roobol, M.J., Tammela, T.L.J., Ciatto, S., Nelen, V., et al. (2009) Screening and Prostate-Cancer Mortality in a Randomized European Study. The New England Journal of Medicine, 360, 1320-1328. https://doi.org/10.1056/NEJMoa0810084 
[4] Mongiat-Artus, P. and Teillac, P. (2006) Dépistage du cancer de la prostate: Synthèse. Annales d Urologie, 40, 106-110. https://doi.org/10.1016/j.anuro.2006.01.009

[5] Perrin, P. (2008) Dépistage du cancer de la prostate: Les arguments «contre». Médecine Nucléaire, 32, 41-45. https://doi.org/10.1016/j.mednuc.2007.11.005

[6] Cassell, A., Yunusa, B., Jalloh, M., Mbodji, M.M., Diallo, A., Ndoye, M., et al. (2019) A Review of Localized Prostate Cancer: An African Perspective. World Journal of Oncology, 10, 162-168. https://doi.org/10.14740/wjon1221

[7] Ferlay, J.E.M., Lam, F., Colombet, M., Mery, L., Pineros, M., Znaor, A., Soerjomataram, I., et al. (2019) Global Cancer Observatory: Cancer Tomorrow. International Agency for Research on Cancer, Lyon. https://gco.iarc.fr/tomorrow

[8] Tengué, K., Kpatcha, T.M., Botcho, G., Leloua, E., Amavi, A.K., Sikpa, K., Sewa, E., Anoukoum, T., Amegbor, K. and Dosseh, E. (2016) Profilépidémiologique, diagnostique, thérapeutiqueetévolutif du cancer de la prostate au Togo. African Journal of Urology, 22, 76-82. https://doi.org/10.1016/j.afju.2015.06.006

[9] Labbé, D.P., Zadra, G., Yang, M., Reyes, J.M., Lin, C.Y., Cacciatore, S., et al. (2019) High-Fat Diet Fuels Prostate Cancer Progression by Rewiring the Metabolome and Amplifying the MYC Program. Nature Communications, 10, Article No. 4358. https://doi.org/10.1038/s41467-019-12298-Z

[10] Mottet, N., Comford, P., Van der Bergh, R.C.N., Briers, E., De Santis, M., Gillesen, S., Grummet, J., Henry, A.M., Van der Kwast, T.H., Lam, T.B., Masson, M.D., O’Hanlon, S., Oprea-Lager, D.E., Ploussard, G., Van der Poel, H.G., Rouvière, O., Schoots, I.G., Tilki, D., Wiegel, T., Van den Broeck, T., Cumberbatch, M., Farolfi, A., Fossati, N., Gandaglia, G., Grivas, N., Lardas, M., Liew, M., Moris, L. and Willemse, P.-P.M. (2021) EAU-EANM-ESTRO-ESUR-ISUP-SIOG Guidelines on Prostate Cancer in European Association of Urology Pocket Guideline. 2021 Edition, European Association of Urology (EAU), Arnhem, 74-75.

[11] Kupelian, P., Klein, E., Witte, J., Kuppelian, V. and Suh, J. (1997) Familial Prostate Cancer: A Different Disease? Journal of Urology, 158, 2197-2201. https://doi.org/10.1016/S0022-5347(01)68194-1

[12] Westerman, M.E., Gershman, B., Karnes, R.J., Thompson, R.H., Rangel, L. and Boorjian, S.A. (2015) Impact of a Family History of Prostate Cancer on Clinicopathologic Outcomes and Survival Following Radical Prostatectomy. World Journal of Urology, 8, 1115-1122. https://doi.org/10.1007/s00345-015-1738-6

[13] Jansson, K.F., Akre, O., Garmo, H., Bill-Axelson, A., Adolfsson, J., Stattin, P., et al. (2012) Concordance of Tumor Differentiation among Brothers with Prostate Cancer. European Urology, 62, 656-661. https://doi.org/10.1016/j.eururo.2012.02.032

[14] Brandt, A., Bermejo, J.L., Sundquist, J. and Hemminki, K. (2010) Age-specific Risk of Incident Prostate Cancer and Risk of Death from Prostate Cancer Defined by the Number of Affected Family Members. European Urology, 58, 275-280.

https://doi.org/10.1016/j.eururo.2010.02.002

[15] Kamangar, F., Dores, G.M. and Anderson, W.F. (2006) Patterns of Cancer Incidence, Mortality, and Prevalence across Five Continents: Defining Priorities to Reduce Cancer Disparities in Different Geographic Regions of the World. Journal of Clinical Oncology, 24, 2137-2150. https://doi.org/10.1200/JCO.2005.05.2308

[16] Chornokur, G., Dalton, K., Borysova, M.E. and Kumar, N.B. (2011) Disparities at Presentation, Diagnosis, Treatment, and Survival in African American Men, Affected by Prostate Cancer. Prostate, 71, 985-97. https://doi.org/10.1002/pros.21314

[17] Karami, S., Young, H.A. and Henson, D.E. (2007) Earlier Age at Diagnosis: Another 
Dimension in Cancer Disparity? Cancer Detection and Prevention, 31, 29-34. https://doi.org/10.1016/j.cdp.2006.11.004

[18] Naji, L., Randhawa, H., Sohani, Z., Dennis, B., Lautenbach, D., Kavanagh, O., et al. (2018) Digital Rectal Examination for Prostate Cancer Screening in Primary Care: A Systematic Review and Meta-Analysis. The Annals of Family Medicine, 16, 149-154. https://doi.org/10.1370/afm.2205

[19] Richie, J.P., Catalona, W.J., Ahmann, F.R., Hudson, M.A., Scardino, P.T., Flanigan, R.C., et al. (1993) Effect of Patient Age on Early Detection of Prostate Cancer with Serum Prostate Specific Antigen and Digital Rectal Examination. Urology, 42, 365-374. https://doi.org/10.1016/0090-4295(93)90359-I

[20] Stormont, T.J., Farrow, G.M., Myers, R.P., Blute, M.L., Zincke, H., Wilson, T.M. and Oesterling, J.E. (1993) Clinical Stage $B_{O}$ or T1c Prostate Cancer: Nonpalpable Disease Identified by Elevated Serum Prostate-Specific Antigen Concentration. Urology, 41, 3-8. https://doi.org/10.1016/0090-4295(93)90233-Z

[21] Schroder, F.H., Hugosson, J., Roobol, M.J., Tammela, T.L.J., Zappa, M., Nelen, V., et al. (2014) Screening and Prostate Cancer Mortality: Results of the European Randomised Study of Screening for Prostate Cancer (ERSPC) at 13 Years of Follow-up. Lancet, 384, 2027-2035. https://doi.org/10.1016/S0140-6736(14)60525-0

[22] Schroder, F.H., Hugosson, J., Roobol, M.J., Tammela, T.L.J., Ciatto, S., Nelen, V., et al. (2012) Prostate-Cancer Mortality at 11 Years of Follow-up. The New England Journal of Medicine, 366, 981-990. https://doi.org/10.1056/NEJMoa1113135

[23] Carvalhal, G.F., Smith, D.S., Mager, D.E., Ramos, C. and Catalona, W.J. (1999) Digital Rectal Examination for Detecting Prostate Cancer at Prostate Specific Antigen Levels of $4 \mathrm{ng} . / \mathrm{ml}$. or Less. Journal of Urology, 161, 835-839. https://doi.org/10.1016/S0022-5347(01)61785-3

[24] Okotie, O.T., Roehl, K.A., Han, M., Loeb, S., Gashti, S.N. and Catalona, W.J. (2007) Characteristics of Prostate Cancer Detected by Digital Rectal Examination Only. Urology, 70, 1117-1120. https://doi.org/10.1016/j.urology.2007.07.019

[25] Gosselaar, C., Roobol, M.J., Roemeling, S. and Schröder, S.H. (2008) The Role of the Digital Rectal Examination in Subsequent Screening Visits in the European Randomized Study of Screening for Prostate Cancer (ERSPC), Rotterdam. European Urology, 54, 581-588. https://doi.org/10.1016/j.eururo.2008.03.104

[26] Thompson, I.M., Pauler, D.K., Goodman, P.J., Tangen, C.M., Lucia, M.S., Parnes, H.L., et al. (2004) Prevalence of Prostate Cancer among Men with a Prostate-Specific Antigen Level $\leq 4.0 \mathrm{ng}$ per milliliter. The New England Journal of Medicine, 350, 2239-2246. https://doi.org/10.1056/NEJMoa031918 


\section{Appendix 1: Questionnaire}

\section{Practitioner's Characteristics}

1) Age: years

2) Sexe: $F(\quad) \quad M(\quad)$

3) Medical practice lenght (months): $\leq 60(\quad)>60$ and $\leq 120(\quad)>120$ and $\leq 180(\quad)>180()$

4) Have you get a lesson on prostate cancer over last 60 months? Yes ( ) No ( )

\section{Prostate Cancer Screening Criteria and Tools}

1) What is (are) the prostate cancer screening criteria?

Age $>50$ years? Yes $($ ) No ( )

Family history of cancer? Yes ( ) No ( )

Voiding symptoms? Yes $(\quad)$ No $(\quad)$

2) What is (are) criteria for prostate cancer screening exclusion?

Age < 50 years: Yes ( ) No ( )

Age $>80$ ans: Yes ( ) No ( )

Patient with other serious ilness: Yes ( ) No ( )

$>$ Patient unable to pay for care: Yes ( ) No ( )

3) What tools do you use for prostate cancer screening?

Digital rectal examination (DRE): Yes ( ) No ( )

$>$ Prostate Specific Antigen test: Yes ( ) No ( )

$>$ Pubic ultrasound: Yes ( ) No ( )

$>$ Rectal ultrasound: Yes ( ) No ( )

$>$ Both of precedent: Yes $(\quad)$ No $(\quad)$

Risk Interpretation and Request for Urological Consultation

Which results do you consider to be abnormal and requiring a urological opinion for cancer detection?

$>$ Family history of cancer ( )

Voiding symptoms ( )

$>$ Concerning DRE

- Prostate enlargement ( )

- Prostate induration ( )

- Prostate irregularity ( )

Concerning PSA

- $>4 \mathrm{ng} / \mathrm{ml}(\quad)$

- Ratio free PSA/Total PSA $<15 \%$ ( )

$>$ Concerning ultrasound

- Heterogenuous prostate ( )

- Nodular prostate ( )

$>$ Concerning all parameters

- Abnormal DRE ( ) 
- abnormal PSA level ( )

- Abnormal DRE + abnormal PSA level ( )

- Abnormal ultrasound ( )

- Abnormal DRE + Abnormal ultrasound ( )

- abnormal PSA level + Abnormal ultrasound ( ) 